\title{
Asymmetric Impact of Reference Point Confidence on Consumer Evaluations
}

\author{
H. Onur Bodur • Neeraj Arora
}

Published online: 23 September 2014

(C) Springer Science+Business Media New York 2014

\begin{abstract}
In this paper, we uncover an interesting interplay between sensitivity to losses and reference point confidence. We define reference point confidence (RPC) and investigate how it moderates the sensitivity to gains and losses within the prospect theory framework. Our results from three studies show that RPC has an asymmetric effect on gain and loss sensitivities. RPC also impacts how consumers evaluate performance levels that match the reference point. These results show that RPC can help explain the heterogeneity in reference point effects across consumers. We empirically identify drivers of RPC for price and non-price attributes.
\end{abstract}

Keywords Reference points $\cdot$ Loss aversion $\cdot$ Reference point confidence $\cdot$ Prospect theory $\cdot$ Hierarchical Bayes model

Past research shows that individuals do not evaluate alternatives in an absolute manner, but relative to a reference point (RP). The reference dependence of evaluations and asymmetric effect of gains and losses are well documented in a number of decision contexts, including gambles [9], donations [13], investment decisions [30], negotiations [27], determination of dividends [40], and consumer choice [11, 18, 24]. Particularly in marketing, reference-dependence is viewed as one of the three major generalizations in consumer choice models [31]. Several papers have demonstrated heterogeneity in reference point effects across individuals $[5,15,17]$. In this paper, we

H. O. Bodur $(\bowtie)$

Marketing Department, John Molson School of Business, Concordia University, Montreal, QC, Canada

e-mail: onur_Bodur@yahoo.com

N. Arora

Wisconsin School of Business, University of Wisconsin-Madison, Madison, WI, USA

e-mail: narora@bus.wisc.edu present a theoretical explanation for heterogeneity in reference point effects across consumers. We view reference point as the consumer's normal performance expectation for a product attribute if they were to buy the product today, similar to earlier research [21, 23, 46]. Although consumers may share the same reference point, they may vary in the conviction or certainty with which they hold this reference point. In this paper we refer to this conviction or certainty as reference point confidence (RPC) and show that the heterogeneity in RPC can result in systematic effects on the sensitivity to performance levels deviating from the reference point.

Several of our findings are noteworthy. First, the impact of losses are amplified for customers with high RPC compared to those with low RPC, implying a higher sensitivity to losses for high RPC customers. The rationale for this expectation is that reference point confidence has a "crystallizing" effect in defining the gap between the reference point and the performance level [44]. Second, the moderating effect of RPC on losses is higher than it is for gains. Higher reference point confidence helps define the disconfirmation with greater clarity and the increased clarity of the disconfirmation information is expected to have a greater impact in the domain of losses (negative information) than gains (positive information) consistent with literature in negativity bias [3, 38]. As a result of this differential effect, high RPC customers' evaluations will exhibit higher loss aversion. Finally, RPC also shifts up consumers' evaluation of performance levels at the reference point. That is, a performance that meets expectations results in a higher evaluation by the high RPC customers compared to the low RPC customers. We empirically demonstrate all three of these RPC effects and argue that RPC is an important factor in shaping consumer responses. We also identify product and individual specific determinants of RPC and investigate the impact of these factors on RPC. The joint consideration of consumer reference points and RPC provides valuable direction for product design. When RP and RPC are viewed jointly in a $2 \times 2$ matrix with low and high values of each factor, the 
resulting framework leads to distinct segments in terms of how consumers would evaluate a given product.

We report results from three studies that provide empirical support for the key role played by RPC in customer evaluation of a performance level. The studies also investigate determinants of RPC. In study 1 , we test our model with external reference prices: we manipulate the information that participants use to form RP and RPC and demonstrate the impact of RPC on price evaluation. In study 2, we present further support for the model using measures of internal reference prices and RPC. This provides robustness of our hypotheses to alternate reference point formation mechanisms. In study 3 , we test our model using a non-price attribute and a national sample. Across all three studies, we find convergence of RPC effects with internal or external RP's, with student or national samples, and with price and non-price attributes.

\section{Literature Review}

There is ample evidence in marketing literature, particularly in pricing, that consumers use reference points in evaluation of a given attribute performance. Both studies based on actual purchase data $[4,49]$ and experimental data [16] show that consumers use an internal comparison level (i.e., reference point) in evaluating observed performance levels, consistent with prospect theory [22]. The existence of reference price effects has also been questioned on at least two bases: (a) consumers' price memory and (b) the operationalization of reference prices in scanner based data. We discuss these issues in greater detail next.

\subsection{Memory}

Whether consumers use reference prices in their evaluations has been questioned because buyers often may not accurately remember the prices of items they have recently purchased $[14,46]$. Several authors have found that consumers may vary in their recall accuracy and that consumers with higher price accuracy may share certain characteristics, such as higher involvement in product category [19, 48]. Monroe and Lee [33], however, argue that reference point information (e.g., reference price) may be stored in different memory structures (explicit vs. implicit) and that reference information may still be used even when it is not reflected in recall measures. In line with Monroe and Lee [33], Vanhuele and Drèze [47] use alternative measures of reference price knowledge and find that consumer price knowledge is related to consumer level factors (e.g., loyalty, price search propensity) and product category level factors (e.g., price volatility) in a field experiment.

\subsection{Inferred Reference Point}

A large number of papers using scanner based choice data have demonstrated the existence of reference point effects, mostly with price as the focal attribute. Scanner data based studies, without exception, infer reference price as a function of past prices or current prices. The former are often referred to as memory based and the latter as stimulus based reference prices. Perhaps a major concern about these papers is that they lack a direct measure of reference point [11] and do not attempt to validate the inferred measure. The concern is amplified by a finding by Vanhuele and Drèze [47] where authors report no connection between recency of purchase and price knowledge. This finding is at odds with the widely used weighted average measure of reference price that relies more heavily on recent prices. In the body of knowledge using scanner panel based data, factors such as purchase frequency, brand sampling, deal proneness, having a stock-out, brand loyalty, and frequency of price discounts are found to be related to reference price effects $[17,26,28,36]$. Erdem et al. [15] profiled "reference price shoppers" and distinguished between gain- and loss-sensitive customers. For instance, they found that loss sensitive customers are influenced less by their past brand use (i.e., loyalty), less likely to have a full-time employed household head, and have larger household size. Interestingly, gain sensitive customers do not share any of these characteristics.

In summary, these papers indicate that consumers may display heterogeneity (a) in their recall and knowledge of reference points and (b) in their sensitivity to gains and losses. In this paper, we argue that these two issues are related. Although past research [15] identifies customer characteristics that influence reference point effects, there is a lack of a general theoretical framework explaining how these characteristics shape consumer responses. We contend that consumers may display heterogeneity in reference point confidence, due to a number of factors, such as knowledge, experience, or credibility of reference point information. In turn, the heterogeneity in reference point confidence (RPC) can have an impact on consumer's sensitivity to gains, losses, and expected performance levels.

More recently, while focusing on the differences between articulated and inferred internal reference prices, Thomas and Menon [43] introduce an interesting effect of reference price confidence on internal reference prices. Authors argue that reference price confidence decreases internal reference prices, although the articulated reference price may remain unchanged. Our research provides an alternative viewpoint to how RPC may influence evaluations. We argue that RPC increases the sensitivity to deviations from the reference point and that this effect is stronger for negative deviations (losses) compared to positive deviations (gains). These are two different explanations of how RPC may affect evaluations. We 
contribute to past literature by presenting an alternative effect of RPC and present empirical support for this explanation with price and non-price attributes. Next, we present our predictions and the studies that test these predictions.

\section{Model and Hypotheses}

Guided by prospect theory [45], for a given person, the evaluation y of an attribute can be written as follows:

$$
y(p \mid r)= \begin{cases}y * & \text { if } p=r \\ y *+(p-r) \gamma+\varepsilon & \text { if } p>r, \text { a gain } \\ y *-(r-p) \lambda+\varepsilon & \text { if } p<r, \text { a loss }\end{cases}
$$

where $y$ is determined by the deviation of the attribute (e.g., price) value $p$ from the person's reference point $r$. The parameter $\gamma$ is the gain sensitivity of the given person to the attribute and $\lambda$ is the loss sensitivity. Prospect theory suggests that losses $(p<r)$ loom larger than gains $(p>r)$ or in other words $\lambda>\gamma$. Status quo evaluation $y$ corresponds to the case when performance equals expectations $(p=r)$. The above linear specification of the evaluation is similar to Bell and Lattin [5] and Hardie et al. [18] where y determines consumer choice. It is assumed that the errors $\varepsilon$ are independent and identically distributed $\mathrm{N}\left(0, \sigma^{2}\right)$. The error term for both gains and losses is assumed to be the same.

In our empirical contexts, the dependent variable $y$ is a direct measure of purchase intention and price attractiveness as stated by a given person. As explained in the empirical section, the reference point $r$ is directly elicited and so is the status quo evaluation $y^{*}$ for the condition when $p=r$. We vary the independent variable $p$ in order to estimate $\lambda$ and $\gamma$, the two primary parameters of interest. To account for heterogeneity in gain and loss sensitivities we assume that the $2 \times 1$ vector $[\gamma, \lambda]_{\mathrm{i}}$ across all $\mathrm{i}$ respondents to be distributed bivariate Normal $\left(\left[\left(\begin{array}{c}\bar{\gamma} \\ \bar{\lambda}\end{array}\right), T\right]\right.$. The parameters $\bar{\gamma}$ and $\bar{\lambda}$ are the average gain and loss sensitivity in the sample and $\mathrm{T}$ is the $2 \times 2$ covariance matrix. In order to investigate the relationship between gain and loss sensitivities and RPC, we make the following substitution in Eq. (1):

$\bar{\gamma}=\bar{\gamma}_{0}+\rho_{G} R P C$

$\bar{\lambda}=\bar{\lambda}_{0}+\rho_{L} R P C$

Where $\rho_{G}$ and $\rho_{L}$ in Eq. (2) relates the gain and loss sensitivities to RPC. We expect to show that all else equal, higher RPC results in higher sensitivity to gains and losses. An MCMC procedure identical to Arora and Allenby [2] was used to estimate the model.
Consumer uncertainty in reference points has been noted by others as well. Rust, Inman, Jia, and Zahorik [39] conceptualize consumer expectations as a distribution and study how the shape of this distribution changes as a consequence of multiple product experiences. Bordley and LiCalzi [10] view consumer target as a unimodal distribution and demonstrate how such an assumption leads to a utility specification consistent with the predictions of prospect theory. In the context of reference prices, Biswas and Blair [7] and Yadav and Seiders [50] show that internal reference prices in which the consumers had more confidence were more resistant to change when these reference prices were challenged by external price claims such as "regular price" ads. In addition, Thomas and Menon [43] show that repeated exposure to price information increases confidence in reference prices and participants who were more confident had lower response times. Existing research, therefore, suggests the need to carefully study how the prospect theory based predictions relate to reference point confidence.

We expect that reference point confidence will increase the sensitivity to gains and losses. According to prospect theory, an individual compares the performance level on an attribute to her reference point and classifies the offer price as a loss or a gain in the editing stage. Building on attitude certainty literature that documents that attitudes with higher certainty are clearer [44], we argue that reference point confidence has a "crystallizing" effect in defining the disconfirmation between the reference point and the performance level. When RPC is low, however, the reference point is nebulous and the resulting disconfirmation is less clear. Literature in expectation disconfirmation paradigm in the satisfaction literature supports a similar perspective [41].

H1: Gain sensitivity will be higher when reference point confidence is high as opposed to low $\left(\rho_{G}>0\right)$.

A similar argument can be made for situations in which performance level equals the reference point. The propositions and findings of Rust et al. [39] support this prediction. In a longitudinal study, authors found that simply meeting expectations served to reduce uncertainty about the brand expectations and increased evaluations.

$\mathrm{H} 2$ : Loss sensitivity will be higher when reference point confidence is high as opposed to low $\left(\rho_{L}>0\right)$.

Although Erdem et al. [15] found significant effects of household size, loyalty, and type of employment on loss sensitivity, but not on gain sensitivity, a theoretical explanation of this descriptive finding remains unknown. RPC may explain this effect. Specifically, we propose that RPC will have a greater impact on loss sensitivity than on gain sensitivity. Our rationale for this expectation is twofold. Based on negativity bias [3, 38], we expect the "crystallizing" effect of RPC on the 
disconfirmation information to be greater in the domain of losses (negative information) than in the domain of gains (positive information). Secondly, there is an empirical reason to expect the range of performance evaluation in the loss section of the utility curve $\left(y^{*}-\mathrm{y}_{\min }\right)$ to be greater than the range of performance evaluation in the gain section of the utility curve $\left(y_{\max }-y^{*}\right) .{ }^{1}$ For instance, Rust et al. [39] show that participants are more likely to choose the product when the product meets their expectations and show choice indifference only when the product falls below expectations (see Fig. 2 in Rust et al. [39]). These results suggest that evaluations are favorable when expectations are met. In addition, as RPC increases, evaluation of the status quo also shifts up (H3) and there is a higher range of performance evaluation in the loss section of the utility curve than in the gain section of the utility curve. As a result, we expect the impact of RPC on loss sensitivity to be greater than on gain sensitivity.

H3: Evaluation of a performance level that meets the reference point $\left(y^{*}\right)$ will be higher when reference point confidence is high, as opposed to low.

H4: The impact of reference point confidence on loss sensitivity will be higher than the impact of RPC on gain sensitivity $\left(\rho_{L}>\rho_{G}\right)$.

Figure 1 is a schematic representation of our hypotheses above: The RPC is expected to increase the sensitivity to both gains and losses. However, this effect is expected to be higher for losses than gains. For high RPC individuals, the evaluation of a performance level that meets the reference point is expected to be higher than that of low RPC individuals.

If RPC does indeed have an influence on how gains and losses are evaluated, then, it is also theoretically and substantively relevant to investigate the determinants of RPC. We expect to show that RPC is related to individual level factors (such as prior experience with the product). We can capture the impact of such factors on RPC using the following equation:

$R P C_{i}=\Phi D_{i}+\nu_{i}$

where $D$ represents individual specific determinants of RPC and $v$ is the error term. We expect RPC to be related to individual level factors, namely, involvement, experience with the product, and knowledge about the product.

Consumers who are highly involved in a product category are more motivated to process product relevant information thoroughly and more likely to be

\footnotetext{
${ }^{1}$ In all our empirical investigations $y^{*}$ is always higher than the midpoint of the scale.
}

knowledgeable about product attributes [8, 32, 37]. Involvement can increase the encoding, storage, and recall of attribute specific information [42]. Chandreshekaran and Grewal [12] have found that consumers with high involvement are less likely to revise their internal reference point. These findings suggest that involvement is positively related to how strongly consumers hold their reference points.

We also expect past experience with the product and knowledge to be related to RPC. This expectation is consistent with extant work in marketing literature [29]. Yadav and Seiders [50] compared experienced and inexperienced shoppers and found that experienced shoppers had more confidence in their price estimates and were less likely to revise their reference price. Biswas and Blair [7] reported that familiarity is positively related to confidence in price beliefs. Product knowledge is also found to be positively related to confidence with consumers' reference point estimates [6]. As consumers get more experienced and more knowledgeable about the product, they are likely to have a better understanding of what performance levels to expect. We therefore expect that product knowledge and experience with the product to be positively related to reference point confidence.

H5: Reference point confidence will be positively related to consumer's (a) involvement, (b) product knowledge, and (c) experience with the product.

\section{Method}

The reference points about product attributes may be formed based on information from external sources, including commercial (e.g., ads, company websites) and non-commercial sources (e.g., word-of-mouth or product reviews) or maybe be internal and based on direct prior experience with the product $[20,34$, 41]. Further, reference points may pertain to price as well as non-price attributes. To test our hypotheses, we report findings from three separate studies. In study 1 , we focus on external sources of reference prices and vary RPC by manipulating the source credibility of the external price information using a realistic interface, shop-bots. In study 2 , we focus on memory-based reference prices and manipulate RPC by varying product category knowledge and experience. In study 3 , we test our hypotheses using a national sample and a financial product: money market deposit account. With this stimulus, we also extend our RPC findings to a non-price attribute.

\subsection{Study 1}

Participants were asked to evaluate an unfamiliar product category, oil painter kit, so that we could manipulate their 
Fig. 1 RPC effects on attribute evaluation. Solid curve represents high RPC case and dashed curve represents low RPC case

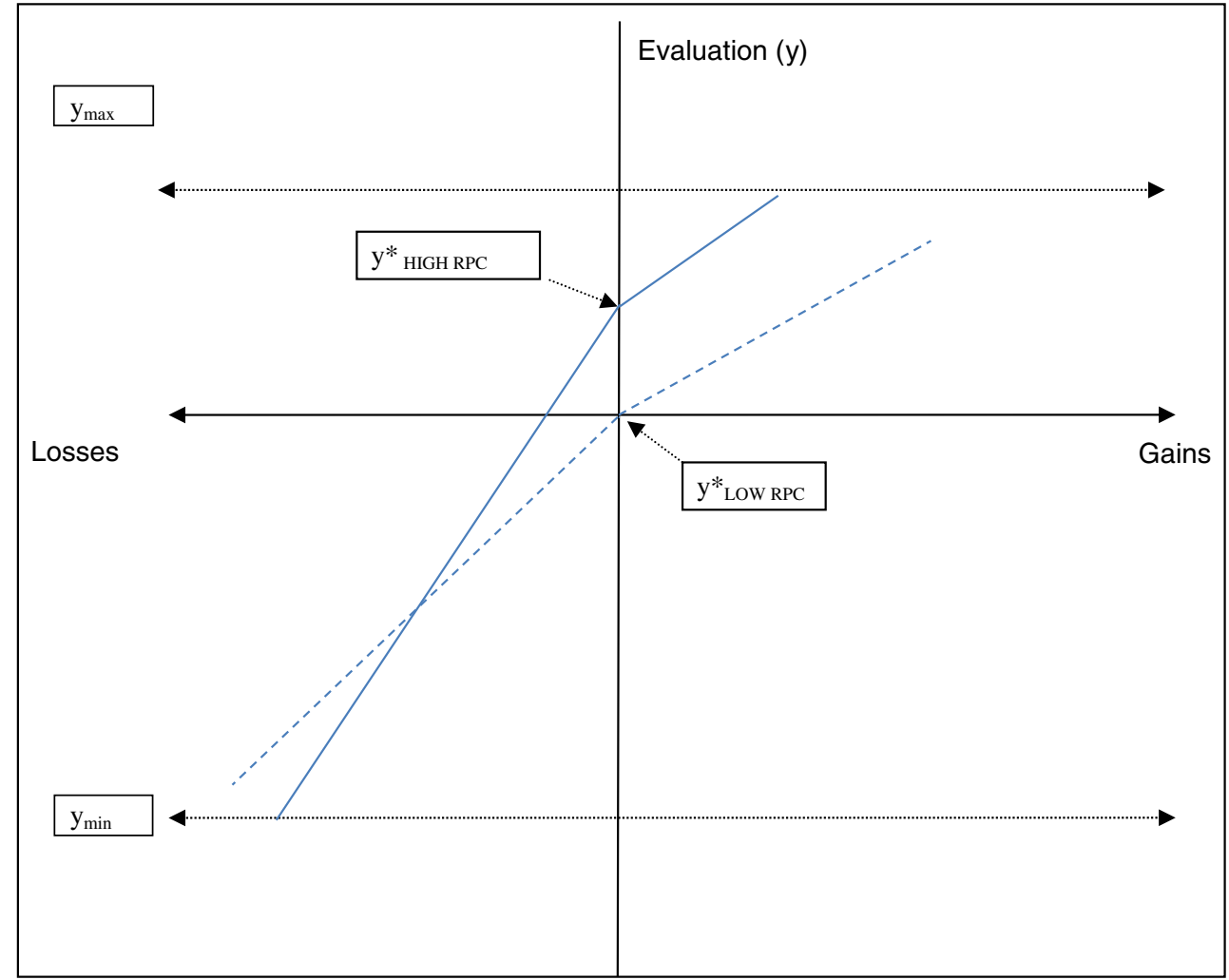

expected prices and RPC externally. Both the expected price and RPC were manipulated via price search results based on a shop-bot: www.pricescan.com. The selection of the product category was based on a pretest $(n=63)$ which revealed that less than $10 \%$ of participants had purchased an oil painter kit in the past. This study manipulates RPC using star ratings of the price source (i.e., retailers), mimicking realistic external price search that consumers conduct. The majority of the consumers report that the Internet is the primary information source before finalizing offline transactions.

Sample and Procedure Ninety two students from a large eastern university participated in study 1 in return for partial course credit. The RPC was manipulated by varying the price source credibility in two conditions. We asked participants to assume that they are taking an oil painting course as an elective and that they need to purchase a starter oil painting kit. Next, participants were presented with the product photo and description without the price. Participants then saw price search results from pricescan.com that listed three retailers offering the product at $\$ 50.17, \$ 50.25$, and $\$ 50.39$. The product price of $\$ 50$ was a realistic price for the product at the time of the study. All the retailers were unfamiliar to the participants and were presented with either a 1-star rating or 5-star ratings. Following the presentation of the price search results, participants were asked to indicate their expected price for the product reviewed and complete measures of reference price confidence. On the following screen, participants were asked to rate the attractiveness of 10 different price levels that were randomly presented. These prices included a price equal to the expected price and prices that were $\$ 5, \$ 10, \$ 15, \$ 20$, and $\$ 25$ above and below the expected price. Finally, participants reported their knowledge, experience, involvement with the products and other demographic variables.

Dependent and Independent Variables Similar to past reference price research [21, 23, 46], we obtained measures of reference price by asking consumers to indicate their normal price expectations. In particular, we asked: "If you were to buy Sennelier Oil Paint Starter Kit today, what is the normal price that you would expect to pay in the market?"

Based on research in reference prices [41, 43] and attitude certainty [35], we used the following items to measure reference price confidence (all on 11-point scales): "To what extent do you believe that the price you stated above is not too high or too low?," "How confident are you that your price estimate was neither too high nor too low?," "How certain are you that your price estimate was neither too high nor too low?," and "How convinced are you that the price you stated above is reasonable?" In this paper, RPC relates to convictions of or confidence with reference points that reflect consumer's performance expectations for a product attribute. Therefore, the adopted RPC measures focus on whether these expectations are reasonable or realistic, rather than whether these 
expectations are the true performance levels. An exploratory factor analysis revealed that all RPC measures loaded on the same factor explaining $71 \%$ of the variance. The average of these measures was used as the RPC index for the rest of the analysis (Cronbach's $\alpha=0.86$ ). Price attractiveness was assessed on a 9-point scale with anchors $1=$ Very unattractive and $9=$ Very attractive. We also obtained measures of whether the task was believable and realistic using 5-point Likert types scales. Participants found the study to be both believable $(M=3.62, t(91)=6.60, p<0.01)$ and realistic $(M=3.61$, $t(91)=6.48, p<0.01$, compared to the midpoint of 3 ).

Study 1 Results The goal of presenting different ratings for retailers was to manipulate RPC between price credibility conditions. Both high and low price credibility groups reported similar expected prices $\left(M_{\text {high }}=\$ 120\right.$ and $M_{\text {low }}=\$ 118$, $t(90)=0.28, p>0.10$ ), but participants who saw prices from 5 -star retailers reported a higher RPC level than those who saw prices from 1-star retailers $\left(M_{\text {high }}=7.21\right.$ and $M_{\text {low }}=6.03$, $t(90)=2.57, p<0.05)$. There was no significant correlation between RP and RPC in our sample $(p>0.10)$. We also did not find any difference in highest and lowest expected prices between the two groups.

Table 1 presents the aggregate estimates for gain and loss sensitivity and RPC coefficients for gains and losses. The $95 \%$ highest posterior density (HPD) credible set for both gain (mean $\left.\bar{\gamma}_{0}=.27\right)$ and loss sensitivities $\left(\right.$ mean $\left.\bar{\lambda}_{0}=.83\right)$ do not include zero. Consumers are more sensitive to losses than to gains $(\lambda / \gamma$ mean $=3.27 ; \mathrm{SD}=1.0){ }^{2}$ The coefficients for the impact of RPC on loss sensitivity (mean $\rho_{L}=.16$ ) is significant as the $95 \%$ HPD credible set does not include zero, ${ }^{3}$ however, the impact of RPC on gain sensitivity was not significant, providing support for hypothesis 1 but not for hypothesis 2 . The attractiveness of the price at the expected price level was not significantly different between low and high price credibility conditions. We do not find evidence in support of hypothesis 3. Finally, we expected the impact of RPC on loss sensitivity to be greater than its impact on gain sensitivity. Because $\rho_{L}$ is greater than $\rho_{G}(=0)$ our results support hypothesis 4 .

\subsection{Study 2}

Unlike the previous study participants were asked to indicate their memory based reference prices for two product categories. They evaluated multiple price levels that reflected gains and losses for each participant. Such a study design allowed us to test our hypotheses and the impact of RPC in two additional product categories.

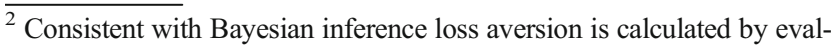
uating the ratio of loss and gain parameters from posterior draws.

${ }^{3}$ Posterior draws are used to conduct parameter related hypothesis tests.
}

Sample and Procedure One hundred and twelve students from a large eastern university participated in study 2 in return for partial course credit. On a computer, each participant reviewed and evaluated prices in two product categories. The participants were presented with the description and photo of either a USB memory key (Kingston Data Traveler USB 2.0, 8GB) or a digital atomic clock (La Crosse Atomic Wall Clock with Temperature Display) first. At the time of the study, based on shop bot results at stores accessible to participants, USB flash key and atomic clock were offered at a mean price of $\$ 37.58$ and $\$ 37.96$, respectively. These expected prices were not significantly different from each other $(p<0.05)$. As expected, participants were more knowledgeable about, had more experience with and had more involvement in USB flash keys than atomic clocks (for all $t(24)>2.7$, $p<0.05$ ).

Following the presentation of the product information, participants were asked to indicate their expected price for the product reviewed and complete measures of reference price confidence. On the following screen, participants were asked to rate the attractiveness of 10 different price levels that were randomly presented. These prices included a price equal to the expected price and prices that were 10,20,30, 40, and $50 \%$ above and below or the expected price. Participants continued to repeat this task for the second product. Product order was counterbalanced. Finally, participants reported their knowledge, experience, involvement with the products and other demographic variables.

Dependent and Independent Variables The measures for reference price and reference price confidence, and price attractiveness were identical to study 1 . The four item measure of RPC loaded on a single factor and explained $79.6 \%$ of the variance with a Cronbach's $\alpha$ of 0.91 . In addition, we obtained measures of product knowledge using 3-items $(\alpha=0.86)$, product experience using 4-items $(\alpha=0.94)$, product involvement using Zaichkowsky's [51] 10 item involvement scale $(\alpha=0.95)$.

Study 2 Results Our primary goal of study 2 was to test our hypotheses model with memory-based price expectations. We selected two different products with which consumers had high and low levels of experience in order to increase the generalizability of the model. There were no order effects of product presentation. There was also a significant negative correlation between RP and RPC in our sample for USB key $(r=-0.38, p<0.05)$ and atomic clock $(r=-0.34, p<0.05)$. The expected reference price was higher for the atomic clock than the USB key $\left(M_{a t c}=\$ 54, M_{u s b}=\$ 34, t(111)=-4.46, p<0.01\right)$. For the low experience product, participants were less accurate with expected price. Participants were more experienced, more knowledgeable, and more involved with USB keys than with atomic clocks (all $p<0.01$ ). A greater percentage of 
Table 1 Model estimates

\begin{tabular}{|c|c|c|c|c|}
\hline Coefficient Description & $\begin{array}{l}\text { Study } 1 \\
\text { Oil Painting Kit } \\
\text { Estimate }^{\text {a }} \\
(95 \% \text { HPD })^{a}\end{array}$ & $\begin{array}{l}\text { Study } 2 \\
\text { USB Key } \\
\text { Estimate }^{\mathrm{a}} \\
(95 \% \text { HPD })^{\mathrm{a}}\end{array}$ & $\begin{array}{l}\text { Study } 2 \\
\text { Clock } \\
\text { Estimate }^{\mathrm{a}} \\
(95 \% \text { HPD) }\end{array}$ & $\begin{array}{l}\text { Study } 3 \\
\text { Money Market } \\
\text { Deposit Account } \\
\text { Estimate }{ }^{\mathrm{a}} \\
\text { (95\% HPD) }\end{array}$ \\
\hline $\operatorname{Gain}\left(\bar{\gamma}_{0}\right)$ & $\begin{array}{l}\mathbf{0 . 2 7} \\
(0.16,0.37)\end{array}$ & $\begin{array}{l}\mathbf{0 . 3 1} \\
(0.23,0.40)\end{array}$ & $\begin{array}{l}\mathbf{0 . 3 3} \\
(0.25,0.42)\end{array}$ & $\begin{array}{l}\mathbf{0 . 2 8} \\
(0.25,0.32)\end{array}$ \\
\hline $\operatorname{Loss}\left(\bar{\lambda}_{0}\right)$ & $\begin{array}{l}\mathbf{0 . 8 3} \\
(0.71,0.95)\end{array}$ & $\begin{array}{l}\mathbf{0 . 9 4} \\
(0.86,1.02)\end{array}$ & $\begin{array}{l}\mathbf{0 . 8 8} \\
(0.80,0.96)\end{array}$ & $\begin{array}{l}\mathbf{0 . 2 5} \\
(0.21,0.29)\end{array}$ \\
\hline$R P C \operatorname{Gain}\left(\rho_{\mathrm{G}}\right)$ & $\begin{array}{l}-0.10 \\
(-0.21,0.01)\end{array}$ & $\begin{array}{l}-0.02 \\
(-0.11,0.07)\end{array}$ & $\begin{array}{l}-0.08 \\
(-0.16,0.01)\end{array}$ & $\begin{array}{l}0.03 \\
(-0.004,0.07)\end{array}$ \\
\hline$R P C \operatorname{Loss}\left(\rho_{L}\right)$ & $\begin{array}{l}\mathbf{0 . 1 6} \\
(0.05,0.28)\end{array}$ & $\begin{array}{l}\mathbf{0 . 2 4} \\
(0.16,0.32)\end{array}$ & $\begin{array}{l}\mathbf{0 . 1 2} \\
(0.05,0.2)\end{array}$ & $\begin{array}{l}\mathbf{0 . 0 8} \\
(0.04,0.12)\end{array}$ \\
\hline$N$ & 92 & 112 & 112 & 158 \\
\hline
\end{tabular}

${ }^{\mathrm{a}}$ The hierarchical Bayes model estimates are presented. The coefficients in bold are significant ( $95 \%$ HPD does not include 0)

participants reported purchasing a USB key in the past 6 months $(80.4 \%)$ compared to atomic wall clocks $(5.4 \%)$. The average RPC with USB keys was higher than RPC with atomic clocks $\left(M_{\text {High } R P C}=7.65\right.$ and $M_{\text {Low } R P C}=6.11, t(111)=$ $6.62, p<0.01)$. These findings converge with other research findings that reported higher confidence levels in expectations about products in which consumers had higher purchase frequency and experience [41, 43].

Overall pattern of evaluations are presented at the aggregate level in Fig. 2a. The $y$ axis represents the average evaluation of the alternative. The $x$ axis represents gains and losses with respect to the participant's reference point. The high and low RPC groups, obtained based on a median split, react differently to gains and losses: The evaluations of gains were higher for the high RPC individuals compared to low RPC individuals. High RPC individuals also evaluated a price that met their expectation more positively than low RPC individuals. Next, we present model estimates at the product level.

Table 1 presents the aggregate estimates for gain and loss sensitivity and RPC coefficients for gains and losses using hierarchical Bayes model estimation. For USB keys and atomic clock, both gain (mean $\bar{\gamma}_{0}=0.31$ and 0.33 ) and loss sensitivities (mean $\bar{\lambda}_{0}=0.94$ and 0.88 ) were significant. As expected, consumers were more sensitive to losses than to gains. Also, loss aversion was higher for high RPC product $(\lambda / \gamma$ mean $=3.11, \mathrm{SD}=0.69)$ than for low $\mathrm{RPC}$ product $(\lambda / \gamma$ mean $=2.70, \mathrm{SD}=0.46)$. The coefficients for the impact of RPC on loss sensitivity were significant for both USB key $\left(\rho_{L}=0.24\right)$ and for atomic clock $\left(\rho_{L}=0.12\right)$ at $\alpha<0.05$, however, the impact of RPC on gain sensitivity was not significant. This finding also suggests that the impact of RPC on gain and loss sensitivities is asymmetric $\left(\rho_{L}>\rho_{G}\right)$ consistent with hypothesis 4 .
Study 2

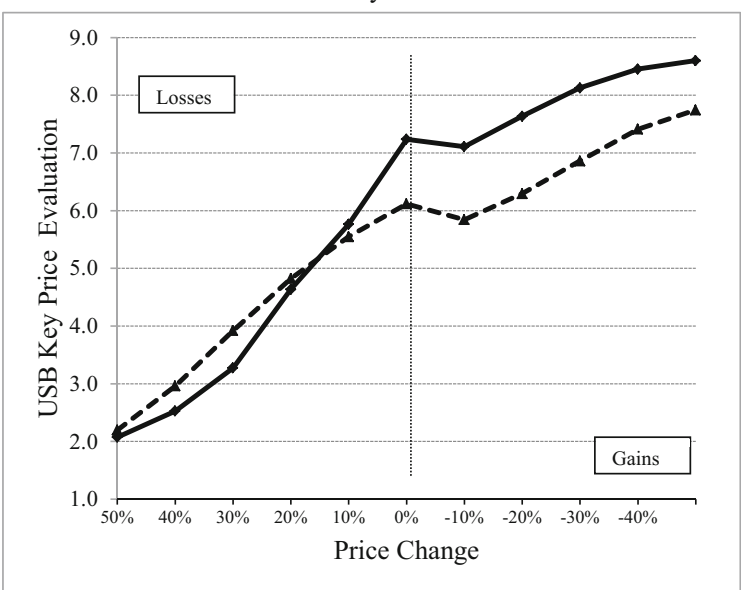

Study 3

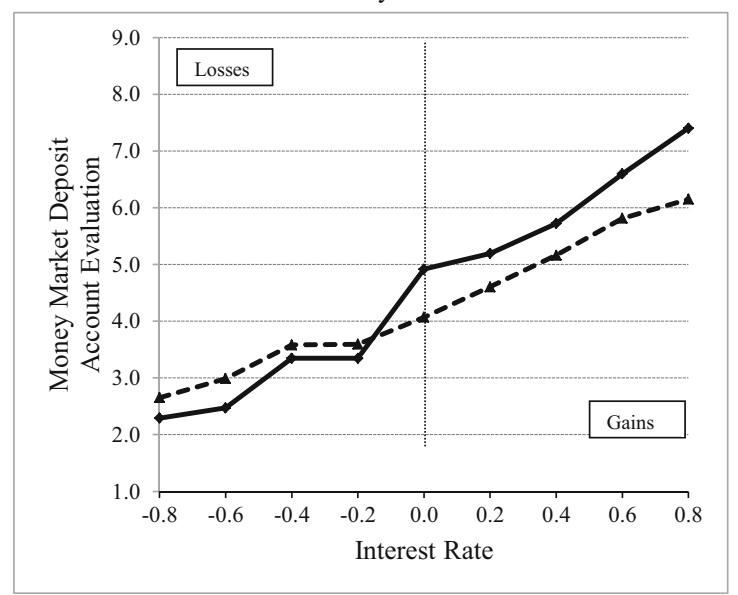

Fig. 2 RPC effects on evaluation. Solid curve represents high RPC case and dashed curve represents low RPC case 
We compared the price attractiveness for the offer price equal to participants' reference price for the high RPC and low RPC participants. With both USB keys $\left(M_{\text {high }} R_{P C}=7.24\right.$, $\left.M_{\text {low } R P C}=6.12, t_{104}=3.00, p<0.01\right)$ and atomic clock $\left(M_{\text {high } R P C}=6.38, M_{\text {low } R P C}=5.53, t_{104}=2.30, p<0.05\right)$, there was a significant difference, providing support for hypothesis 3. We also found that price attractiveness at the expected price was higher for the USB key compared to the atomic clock $\left(M_{U S B}=6.64, M_{\text {clock }}=5.99, t_{111}=4.16, p<0.01\right)$.

Next, we regressed RPC on product category involvement, experience, and knowledge for both categories: $\mathrm{RPC}=3.80+$ 0.04 (involvement) +0.72 (knowledge) +0.34 (experience) . There was no indication of multicollinearity (all tolerance $>0.5$ and all $\mathrm{VIF}<2$ ) and the model was significant at $p<0.01$. As expected all coefficients were positive, however, only knowledge and experience were significant at $p<0.05$ (t-values of 3.85 and 2.45, respectively). At the product category level, the regression analysis provided similar results with USB key with significant coefficients for knowledge and experience ( 0.56 and 0.55 , respectively, $p<0.05)$. With atomic clock, only knowledge was significant $(0.86, p<0.01)$. Given that clock was the low experience product, this result may be due to lack of variance in experience.

Discussion of Findings In study 2, we investigated the impact of RPC on gain and loss sensitivities with memory-based reference prices two different products. The results are consistent in both products: RPC increases loss sensitivity (hypothesis 2), but not gain sensitivity. This finding also provides support for asymmetric impact of RPC on gain and loss sensitivities (hypothesis 4). The impact of RPC on evaluation of the 'status quo' price (that is offer price equal to reference price) was significant. Finally, we found partial support for the impact of knowledge and experience on RPC.

\subsection{Study 3}

In this study we used a financial product, money market deposit account, and tested RPC effects with interest rate, a non-price attribute. We used an internet panel based sample from a population that is likely to be familiar with the product category. We developed a web-based dynamic questionnaire that allowed online creation of alternatives. In order to avoid framing an alternative as a gain or a loss, we asked the participants to evaluate a set of alternatives that were customized using their own reference point. As before, individual level estimates were obtained using a hierarchical Bayes model.

Sample Profile The participants for this study were members of a web panel managed by MarketTools. We restricted participants to be U.S. residents who were at least 21 years old and were employed full time. Invitation to participate in the study was sent to qualified panelists, resulting in a total of 158 complete and usable surveys. The sample consisted of $49.4 \%$ females and the median age was 40 . More than half the sample had income levels above $\$ 60,000(59.5 \%)$ and $60.8 \%$ of the sample had completed an undergraduate or graduate degree. The median household size was 2 . As in previous studies, we observed variance in RPC $\left(M_{R P C}=6.05, \mathrm{SD}=2.76\right)$. There was also a weak, but significant negative correlation between $\mathrm{RP}$ and RPC $(r=-0.35, p<0.05)$.

Procedure Following the introduction to the study on the survey website, participants were asked to indicate their interest rate expectation for money market deposit accounts and the strength associated with the expectation they stated. Next, we asked participants to evaluate a total of 9 money market deposit account alternatives that varied on interest rate. These alternatives were customized for each participant by adding or subtracting four equal increments to the interest rate expectation the participant provided and by presenting an alternative with an interest rate equal to the participant's stated expectation. These alternatives were presented in a random order and an evaluation of each alternative was obtained from the participants.

Measures RP was measured by asking the participants to indicate the interest rate they expect to get if they were to open a money market deposit account today. RPC was measured by using a two-item scale: "How confident are you that you can get the interest rate you just stated (x\%)" and "how certain are you that you can get the interest rate you just stated $(\mathrm{x} \%)$ ". The dynamic nature of the survey allowed replacing " $x$ " with the expected interest rate. Participants rated each money market account alternative presented by answering the question "how likely would you be to open a money market deposit account" using an 11-point scale (with anchors $1=$ Extremely Unlikely and $11=$ Extremely Likely). We also obtained individual level measures that assessed relevance of product category, knowledge, and relevant demographic variables (e.g., income, primary decision maker, previous money market deposit account purchases).

Study 3 Results Model estimation was done as in earlier studies. Table 1 reports the aggregate gain and loss estimates. Both gain and loss coefficients were statistically significant $\left(\bar{\gamma}_{0}=.28\right.$ and $\left.\bar{\lambda}_{0}=.25\right)$. However, consumers were not more sensitive to losses than gains $(\lambda / \gamma$ mean $=0.89, \mathrm{SD}=$ $0.10)$ with money market deposit accounts. In their survey paper Briesch et al. [11] find that reference effects vary by context and how the reference price is operationalized. Although we find evidence consistent with loss aversion in studies 1 and 2 we do not find such evidence in study 3 . The coefficients for the impact of RPC on loss sensitivity were 
significant $\left(\rho_{L}=.25\right)$, however, there was no significant impact of RPC on gains. We also find that RPC has a greater impact on loss sensitivity than gain sensitivity, providing support for hypothesis $4\left(\rho_{L}>\rho_{G}\right)$

We compared the evaluation of alternatives that are equal to the expected interest rate for low and high RPC groups (median split). Consistent with hypothesis 3, high RPC group had a higher evaluation of the alternative that met their expectation compared to the low RPC group $\left(M_{\text {Low } R P C}=4.07, M_{H i g h ~ R P C}=\right.$ $\left.4.92, t_{156}=-2.26, p<0.05\right)$. Overall, results of study 3 provide support for RPC effects on evaluation.

\section{Discussion}

In this research, we uncover an interesting interplay between reference point confidence and the sensitivity to gains and losses within the prospect theory framework. Our purpose was to investigate whether a consumer is more sensitive to gains and losses on a given product attribute when she holds her reference point with higher confidence. Our findings in all three studies suggest that consumers are more sensitive to losses when RPC is high. However, we do not find any effect of RPC on gain sensitivity. The lack of support for RPC effects on gain sensitivity could be explained by negativity bias. As a result, our findings suggest that RPC has an asymmetric effect and higher RPC results in higher loss aversion due to increased loss sensitivity. We also find that high RPC individuals provide more favorable evaluations when the expectation is met compared to low RPC individuals.

Other researchers [41] have proposed that higher confidence levels result in greater impact of the disconfirmation on product evaluations. In contrast, Thomas and Menon [43] argue that higher confidence results in a downward shift in reference points. Although both of these explanations may be operational (i.e., RPC may affect both the sensitivity to losses and lead to a downward shift in internal reference point), the pattern of our findings are more consistent with a change in the sensitivity to losses, rather than a shift in the reference point. In the context of study 3 , higher interest rates of money market accounts would translate into higher gains and, if the internal reference point is shifting downward as a function of RPC, we should be more likely to observe increased sensitivity in the domain of gains, rather than losses. However, consumers in study 3 were more sensitive to offers below the reference point (losses) than those above the articulated reference point (gains). Our findings across three studies are in line with a change in sensitivity explanation. The confidence level in reference points results in changes in the sensitivity to losses rather than merely causing a shift in the reference point. However, further research is necessary to investigate conditions under which each explanation is operational.
Considered jointly, consumer reference points and RPC could provide valuable direction for product design. When RP and RPC are viewed jointly in a $2 \times 2$ matrix with low and high values of each factor, the resulting framework leads to distinct segments in terms of how consumers would evaluate a given product. The segment with high RP / high RPC is the most difficult to satisfy. In this segment, meeting or exceeding consumer expectations is difficult and the failure to do so likely results in a strong negative reaction by the consumers. For brands that can provide high levels of performance consistently, this segment can be rewarding. While meeting high RP's is difficult, simply meeting these expectation may result in higher brand evaluations in the high RP/high RPC segment than in the high RP/low RPC segment. In contrast, for the low $\mathrm{RP} /$ low RPC segment it is easier to exceed expectations, however, these efforts may not translate into major changes in brand evaluations due to lack of RPC effect on gain sensitivity. Meeting low expectations is easier for brands, yet only pays off in the low RP/high RPC segment.

In the paper, we find that certain individual level factors relate positively with RPC (e.g., product knowledge and experience). These and other individual level factors can be used to profile segments based on the RP/RPC criteria. This offers significant potential especially in a multi-attribute context where it may not be feasible to fulfill consumer expectations on every attribute of a product. RPC could help inform product attributes that are critical with regard to meeting consumer expectations.

An important finding in this research is that not only are gain and loss sensitivities asymmetric in prospect theory, the impact of RPC on gains and losses is also asymmetric. The empirical findings suggest that high RPC amplifies losses but not gains. A direct implication is that loss aversion is higher for consumers with high RPC reference points. This finding highlights the importance of meeting expectations (to avoid losses) on high RPC attributes than to exceed expectations, as is also suggested by Rust et al. [39]. Although the current research focuses on the single attribute case, future research can investigate the role of RPC in the multiple attribute case.

Finally, the notion of RPC can also be operationalized using proxy measures such as price dispersion across stores, or over time, providing the opportunity to study RPC effects with scanner panel data and assessing the generalizability of the reported effects to other product categories and more realistic behavioral measures. In this research, we experimentally manipulated RPC (e.g., study 1) to improve the internal validity and used self-reports of RPC to demonstrate the effectiveness of our manipulations, to improve the mapping of the RPC construct in our data, and to document the heterogeneity in RPC across study participants. Future research is necessary to investigate whether RPC effects observed in this study hold with alternative (self-reported or inferred) measures of RPC with price or other attributes. Our dependent 
variable was stated price attractiveness and purchase intent. It would be instructive to continue this investigation in the context where the dependent variable is choice in the marketplace and reference points and RPC are determined endogenously [25]. An even more direct comparison of gains and losses would involve gambles or parameter-free utility elicitation [1] that also incorporates diminishing sensitivity for gains and losses.

\section{References}

1. Abdellaoui M (2000) Parameter-free elicitation of utility and probability weighting functions. Manag Sci 46:1497-1512

2. Arora N, Allenby GM (1999) Measuring the influence of individual preference structures in group decision making. J Mark Res 36: 476-487

3. Baumeister RF, Bratslavsky E, Finkenauer C, Vohs KD (2001) Bad is stronger than good. Rev Gen Psychol 5:323-370

4. Bell DR, Bucklin RE (1999) The role of internal reference points in the category purchase decision. J Consum Res 26: 128-144

5. Bell DR, Lattin JM (2000) Looking for loss aversion in scanner panel data: the confounding effect of price response heterogeneity. Mark Sci 19:185-200

6. Biswas A, Sherrell DL (1993) The influence of product knowledge and brand name on internal price standards and confidence. Psychol Mark 10:31-47

7. Biswas A, Blair EA (1991) Contextual effects of reference prices in retail advertisements. J Mark 55:1-12

8. Bloch PH, Richins ML (1983) A theoretical model for the study of product importance perceptions. J Mark 3:69-82

9. Booij A, van de Kuilen G (2009) A parameter-free analysis of the utility of money for the general population under prospect theory. $J$ Econ Psychol 30:651-666

10. Bordley R, LiCalzi M (2000) Decision analysis using targets instead of utility functions. Decisions Econ Finan 23:4-25

11. Briesch RA, Krishnamurthi L, Mazumdar T, Raj SP (1997) A comparative analysis of reference price models. J Consum Res 24: 202-214

12. Chandreshekaran R, Grewal D (2003) Assimilation of advertised reference prices: the moderating role of involvement. J Retail 79: 53-62

13. Desmet P, Feinberg FM (2003) Ask and ye shall receive: the effect of the appeals scale on consumers' donation behavior. J Econ Psychol 24:349-376

14. Dickson PR, Sawyer AG (1990) The price knowledge and search of supermarket shoppers. J Mark 54:42-54

15. Erdem T, Mayhew G, Sun B (2001) Understanding reference-price shoppers: a within- and cross-category analysis. J Mark Res 38:445-458

16. Grewal D, Monroe KB, Krishnan R (1998) The effects of pricecomparison advertising on buyers' perceptions of transaction value, and behavioral intentions. J Mark 62:46-59

17. Han S, Gupta S, Lehmann DR (2001) Consumer price sensitivity and price thresholds. J Retail 77:435-456

18. Hardie BGS, Johnson EJ, Fader PS (1993) Modeling loss aversion and reference dependence effects on brand choice. Mark Sci 12: 378-394

19. Helgeson JG, Beatty SE (1987) Price expectation and price recall error: an empirical study. J Consum Res 14:379-387

20. Holak SL, Lehmann DR, Sultan F (1987) The role of expectations in the adoption of innovative consumer durables: some preliminary evidence. J Retail 63:243-259
21. Jacobson R, Obermiller C (1990) The formation of expected future price: a reference price for forward-looking consumers. J Consum Res 16:420-432

22. Kahneman D, Tversky A (1979) Prospect theory: an analysis of decision making under risk. Econometrica 47:263291

23. Kalwani M, Yim CK (1992) Consumer price and promotion expectations: an experimental study. J Mark Res 29:90-100

24. Kalyanaram G, Winer RS (1995) Empirical generalizations from reference price research. Mark Sci 14:161-169

25. Koszegi B, Rabin M (2006) A model of reference-dependent preferences. Q J Econ 121:1133-1165

26. Krishnamurthi L, Mazumdar T, Raj SP (1992) Asymmetric response to price in consumer brand choice and purchase quantity decisions. $\mathrm{J}$ Consum Res 19:387-401

27. Kristensen H, Gärling T (1997) The effects of anchor points and reference points on negotiation process and outcome. Organ Behav Hum Decis Process 71:85-94

28. Kumar V, Karande K, Reinartz WJ (1998) The impact of internal and external reference prices on hand choice: the moderating role of contextual variables. J Retail 74:401-427

29. Lichtenstein DR, Bearden WO (1989) Contextual influence on perceptions of merchant-supplied reference prices. J Consum Res 16: $55-67$

30. Lin CH, Huang WH, Zeelenberg M (2006) Multiple reference points in investor regret. J Econ Psychol 27:781-792

31. Meyer R, Johnson EJ (1995) Empirical generalizations in the modeling of consumer choice. Mark Sci 14:180-189

32. Meyers-Levy J, Peracchio LA (1996) Moderators of the impact of self-reference on persuasion. J Consum Res 22:408424

33. Monroe KB, Lee AY (1999) Remembering versus knowing: issues in buyer's processing of price information. Acad Mark Sci J 27:207226

34. Oliver RL (1980) A cognitive model of the antecedents and consequences of satisfaction decisions. J Mark Res 17:460 469

35. Petrocelli JV, Tormala ZL, Rucker D (2007) Unpacking attitude certainty: attitude clarity and attitude correctness. J Pers Soc Psychol 92:30-41

36. Rajendran KN, Tellis GJ (1994) Contextual and temporal components of reference price. J Mark 58:22-34

37. Richins ML, Bloch PH (1986) After the new wears off: the temporal context of product involvement. J Consum Res 13: 280-286

38. Rozin P, Royzman EB (2001) Negativity bias, negativity dominance, and contagion. Personal Soc Psychol Rev 5:296-320

39. Rust RT, Inman JJ, Jia J, Zahorik AJ (1999) What you don't know about customer-perceived quality: the role of customer expectation distributions. Mark Sci 18:77-92

40. Sonnemans J (2006) Price clustering and natural resistance points in the Dutch stock market: a natural experiment. Eur Econ Rev 50: 1937-1950

41. Spreng RA, Page TJ (2001) The impact of confidence in expectations on consumer satisfaction. Psychol Mark 18:1187-1204

42. Srull TK, Lichtenstein M, Rothbart M (1985) Associative storage and retrieval processes in person memory. J Exp Psychol Learn Mem Cogn 11:316-345

43. Thomas M, Menon G (2007) When internal reference prices and price expectations diverge: the role of confidence. J Mark Res 44: 401-409

44. Tormala ZL, Rucker D (2007) Attitude certainty: a review of past findings and emerging perspectives. Soc Personal Psychol Compass 1:469-492

45. Tversky A, Kahneman D (1991) Loss aversion in riskless choice: a reference-dependent model. Q J Econ 106:1039-1061 
46. Urbany JE, Dickson PR (1991) Consumer normal price estimation: market versus personal standards. J Consum Res 18:45-52

47. Vanhuele M, Drèze X (2002) Measuring the price knowledge shoppers bring to the store. J Mark 66:72-86

48. Wakefield KL, Inman JJ (1993) Who are the price vigilantes? An investigation of differentiating characteristics influencing price information processing. J Retail 69:216-234
49. Winer RS (1986) A reference price model of brand choice for frequently purchased products. J Consum Res 13:250-256

50. Yadav MS, Seiders K (1998) Is the price right? Understanding contingent processing in reference price information. J Retail 74: 311-330

51. Zaichkowsky JL (1985) Measuring the involvement construct. J Consum Res 12:341-350 